\title{
Improving EDM Efficiency with Silicon Carbide Powder-Mixed Dielectric Fluid
}

\author{
M. A. Razak, A. M. Abdul-Rani, and A. M. Nanimina
}

\begin{abstract}
Machining cost for electro-discharge machining (EDM) is high due to longer machining time. EDM efficiency is hypothesize can be increased using powder-mixed dielectric fluid (PMEDM). PMEDM works gradually at low pulse energy and distributes evenly the powder in machining area. PMEDM may lead to improve machined part surface finish, improve material removal rate (MRR) and reduce tool wear rate (TWR). Further investigations on powder concentration and powder particles size for silicon carbide (SiC) PMEDM are proposed. Number of experiments to be conducted is based on Taguchi orthogonal array with three level and two factors. The outcomes are expected capable to increase MRR, improve surface finish, reduce TWR, reduce machining time and reduce machining cost.
\end{abstract}

Index Terms-EDM, SiC PMEDM, EDM efficiency, MRR.

\section{INTRODUCTION}

Most plastic products such as pipe thread protectors, seismic instrument enclosures, nylon plugs and lighting components for offshore rigs are produced by injection molding. EDM is widely used in these plastic injection molds especially in machining mold inserts. EDM uses spark erosion principle for material removal from the workpiece [1]. The sparks occur across a small gap between electrode and work surface which take place in a dielectric fluid [2]. The dielectric fluid becomes ionized in the gap to create a path for each discharge. Kerosene oil is the most widely used dielectric fluid. Alternative, paraffin and mineral oil can also be used. The dielectric fluid in EDM process functioned as spark conductor, flushing medium and also to remove particles of eroded metal as shown in Fig. 1.

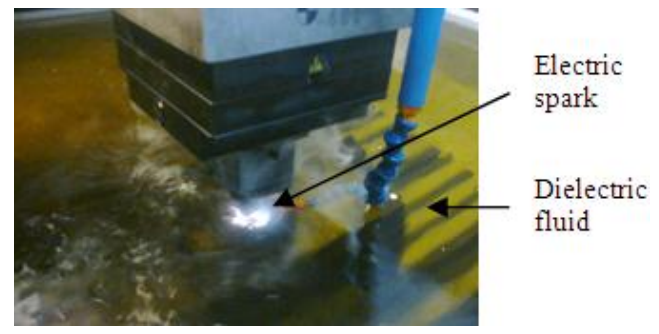

Fig. 1. Electric spark and dielectric fluid in EDM process.

In recent years, new exploratory research works has been initiated to improve EDM process efficiency using PMEDM

Manuscript received January 27, 2014; revised May 30, 2014.

M. A. Razak is with Manufacturing Section, Universiti Kuala Lumpur Malaysian Spanish Institute, Kulim Hi-Tech Park, 09000 Kulim, Kedah, Malaysia (e-mail: alhapis@msi.unikl.edu.my).

A. M. Abdul-Rani and A. M. Nanimina are with Mechanical Engineering Department, Universiti Teknologi Petronas, Bandar Seri Iskandar, 31750 Tronoh, Perak, Malaysia.
[3]. The powder particles help to improve the sparking efficiency during the ignition process [4]. Fig. 2 shows a schematic diagram of a normal single electrical discharge in a spark gap without and with suspended particles [5]. It was noted that the addition of powders led to an increase in gap size that subsequently result in a reduction in electrical discharge power density.
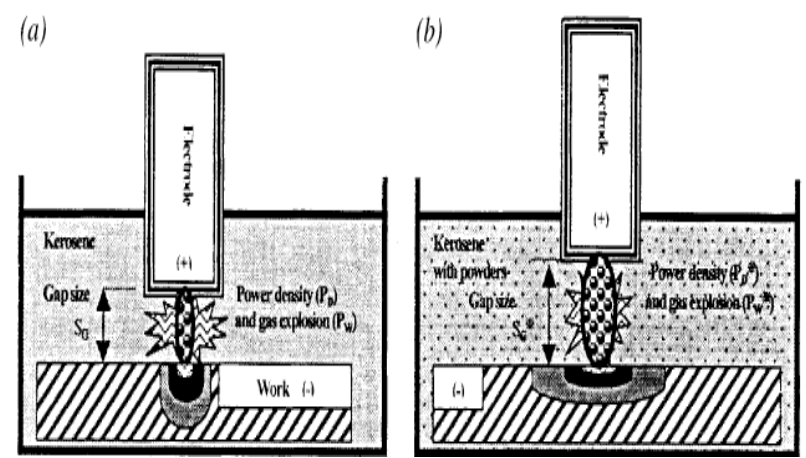

Fig. 2. The electric discharge for single power pulse (a) without powder and (b) with powders [5].

In PMEDM, powders can be suspended into dielectric fluid in the same tank or separated tank as shown in Fig. 3 and Fig. 4. The use of stirrer and circulating pump is to ensure the uniformity distribution of powder.

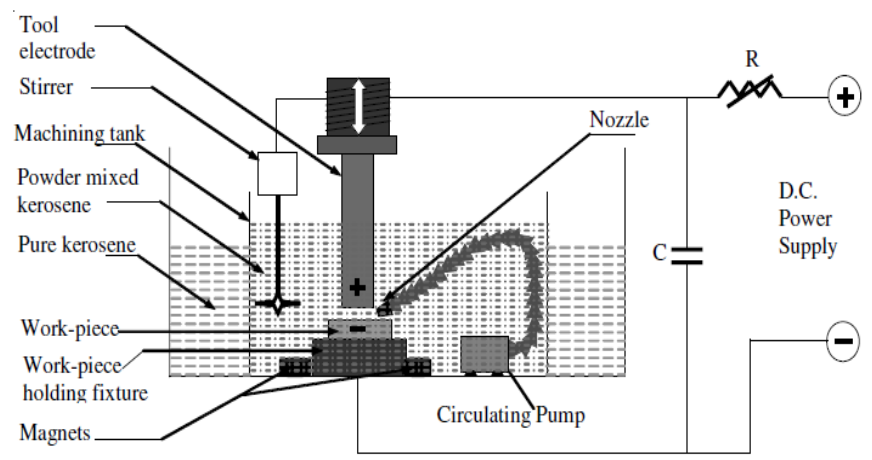

Fig. 3. PM-EDM schematic line diagram [6].

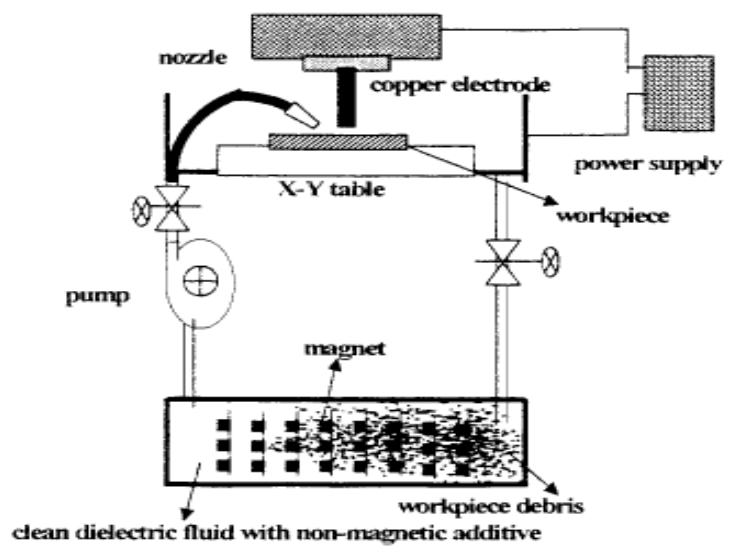

Fig. 4. Filter system used for the EDM during experiments [5]. 
PMEDM may lead to improve machined part surface finish, improve MRR and reduce TWR by increase the gap between the workpiece and electrode [7]. There are still many gaps left unanswered by these researches. Zain et al. [8] carried out the experiments to investigate the influence of Tantalum Carbide $(\mathrm{TaC}) \mathrm{PMEDM}$ on stainless steel workpiece at various levels of peak current and powder concentration. The powder concentration values used were $5 \mathrm{~g} / \mathrm{l}, 10 \mathrm{~g} / \mathrm{l}$ and $15 \mathrm{~g} / \mathrm{l}$. The experiments were conducted in a separate machining tank. The MRR and surface roughness ( $\mathrm{Ra}$ ) were found increased by increasing the current. However the powder concentration behavior was not uniformed. Likely the same study has been done by Rizi et al. [9] but focused on the powder particles size. SiC PMEDM, Titanium alloy Ti-6Al-4V workpiece, copper electrode with $10 \mathrm{~mm}$ in diameter and $20 \mathrm{~A}$ current were used. The structure of machined surfaces was checked by scanning electron microscope (SEM) as shown in Fig. 5. The results obtained from the study indicate some improvements in surface finish, MRR and slight reduction in TWR with usage of SiC PMEDM.

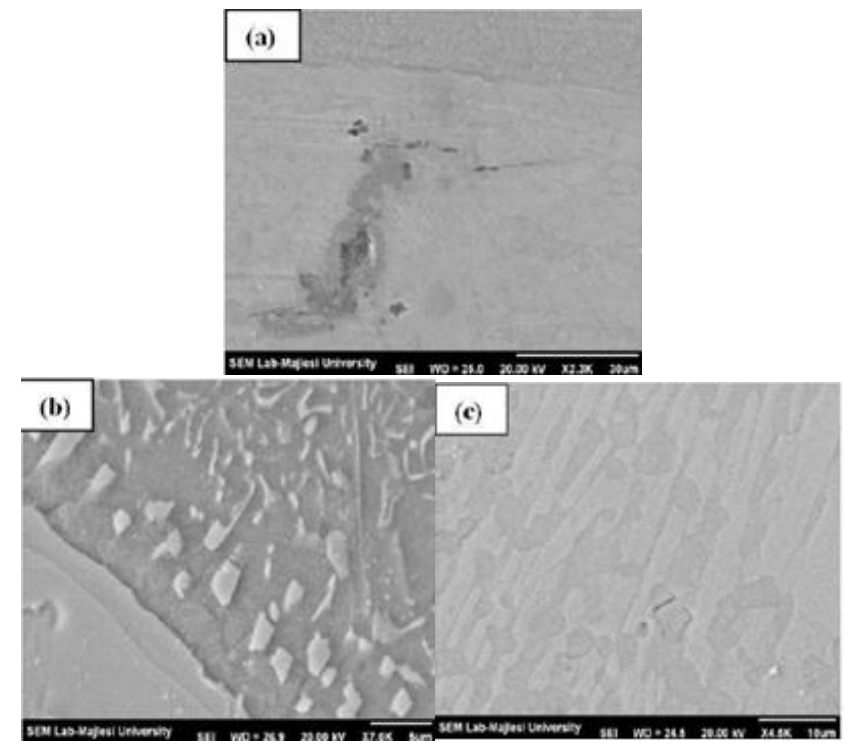

Fig. 5. Scanning electron microscopy image of Titanium alloy surface. a) Before machining $b$ ) machining without using powder $c$ ) machining using powder [9].

Ali et al. [10] also used SiC powder and Ti-6Al-4V alloy workpiece with tungsten carbide electrode in their investigation on the effect of using different powder concentration and discharge energy in micro discharge machining. Result from the study indicated that powder concentrations have some influence on the MRR but less significant compared to discharge current.

Ajay and Anirban [11] suggest that some erosion of the electrode takes place during EDM process. Some of the removed materials get deposited on the machined surface. Common causes to failure of engineering components were due to wear, fatigue and corrosion. PMEDM method was found suitable for surface modification. In the study, Graphite and Aluminum powder were used in EDM Die Steel H11, while Copper and Tungsten powder were used in EDM Die Steel H13 by using Copper and Tungsten-Copper electrode. The researchers suggested that type of powder added gave significant effect to the micro hardness. Tungsten was the best additive to increase micro hardness. It was found that $37 \%$ micro hardness increased for $\mathrm{H} 11$ and 56\% micro hardness increased for H13 with PMEDM compared to normal EDM.

Pichai and Apiwat [12] reported that Tungsten Carbide workpiece were coated with Titanium layer after went through PMEDM process with Titanium powder. $5 \mu \mathrm{m}$ surface coating composed of Titanium and Carbon was obtained at 20A and 50\% duty factor. On the other hand, finite element analysis shows that the temperature profiles and material transformations occur in the workpiece are resulted by high temperature, large deformations and transient operation [13]. Smaller and shallower craters produced by PMEDM compared to normal EDM with the same set of machining conditions.

The role of powder suspended in the dielectric fluid needs deeper clarification before this technique implemented in the industry. This paper proposes further investigations on powder concentration and powder particles size for $\mathrm{SiC}$ PMEDM. The experimental setup must be aligned with other researchers to get a significance data.

\section{PROPOSE INVESTIGATION}

EDM die sinker is widely used in machining mold insert due to its ability to machine complex shape in high accuracy. However the machining cost for EDM process is high. Longer EDM machining time is directly proportionate to higher machining cost. Therefore result from this research work will propose a new technique that able to reduce machining time in EDM process and contribute to reducing mold insert production cost. The objectives of this research work are:

1) To investigate the influence of PMEDM in machining premium stainless mold steel (Stavax®) material in terms of MRR, TWR and Ra.

2) To analyze the reduction machining time of EDM process with PMEDM.

3) To define the optimal powder concentration and size of powder particles to achieve the highest efficiency of EDM process.

\section{Methodology}

In EDM process, kerosene dielectric fluid is normally used. Fig. 6 illustrates the research model for this project. SiC powder will be mixed in the dielectric fluid to get higher MRR. Graphite and copper electrode with diameter $10 \mathrm{~mm}$ will be used in the experiments. For each electrode, nine experiments will be conducted with two factors and three level $\left(3^{2}\right)$ factorial design of experiment as shown in Table I and Table II. An experiment will be executed with normal dielectric fluid for comparison purpose. In total, 20 experiments will be conducted. These experiments will be conducted in separate tank to avoid damage to the original tank and dielectric fluid circulation system. Results from the experiments will be analyzed based on the machining time, MRR, TWR, Ra and also to define the optimal powder concentration and of powder particles size to achieve the highest efficiency of EDM process. Refer to (1), the MRR will be calculated by formula:

$$
\mathrm{MMR}=(\mathrm{Wb}-\mathrm{Wa}) / \mathrm{Tm}
$$


whereas $\mathrm{Wb}$ is the weight of the workpiece before machining; Wa is the weight of the workpiece after machining; and tm is the machining time.

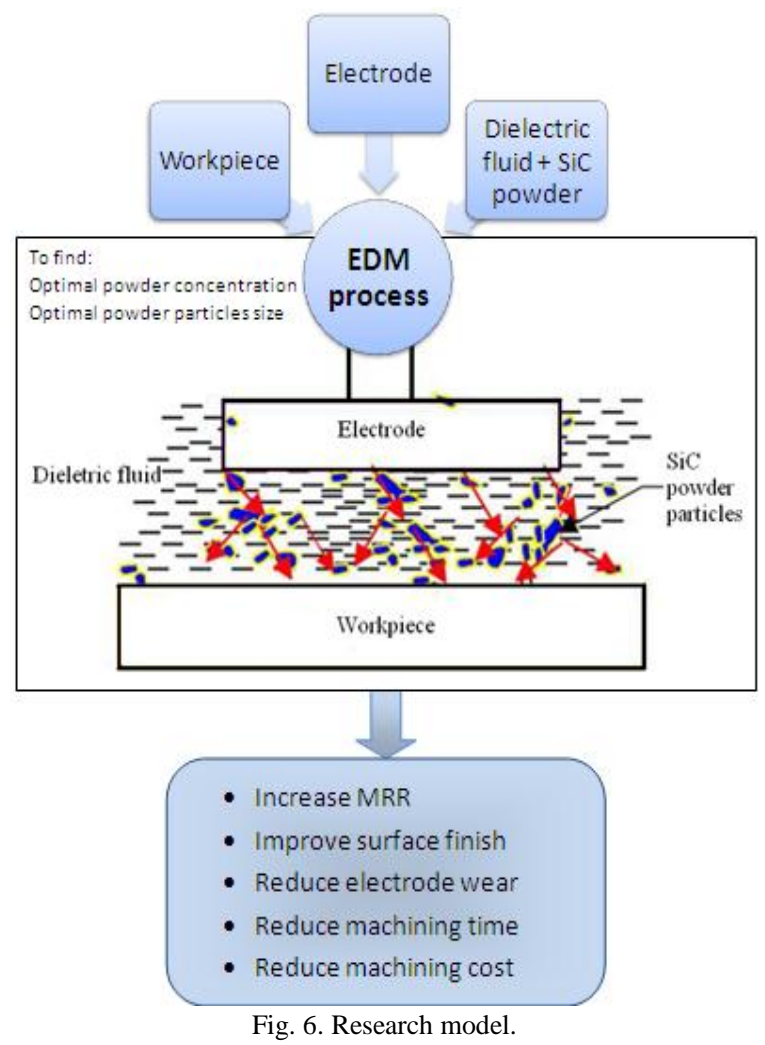

TABLE I: FACTORS AND LEVEL FOR SIC POWDER-MIXED EDM EXPERIMENT

\begin{tabular}{|l|c|c|c|}
\hline \multicolumn{2}{|c|}{ Factor } & \multicolumn{3}{|c|}{ Level } \\
\cline { 2 - 4 } & I & II & III \\
\hline A. Powder concentration $(\mathrm{g} / \mathrm{l})$ & 5 & 10 & 15 \\
& & & \\
\hline B. Powder particles size $(\mu \mathrm{m})$ & 10 & 20 & 30 \\
\hline
\end{tabular}

TABLE II: $3^{2}$ TAGUCHI ORTHOGONAL ARRAY DESIGN FOR SiC

\begin{tabular}{|c|c|c|}
\hline \multirow{2}{*}{ Experiment } & \multicolumn{2}{|c|}{ FowDER-MIXED EDM } \\
\cline { 2 - 3 } & $\mathrm{A}(\mathrm{g} / \mathrm{l})$ & $\mathrm{B}(\mu \mathrm{m})$ \\
\hline 1 & 5 & 10 \\
\hline 2 & 5 & 20 \\
\hline 3 & 5 & 30 \\
\hline 4 & 10 & 10 \\
\hline 5 & 10 & 20 \\
\hline 6 & 10 & 30 \\
\hline 7 & 15 & 10 \\
\hline 8 & 15 & 20 \\
\hline 9 & 15 & 30 \\
\hline
\end{tabular}

\section{EXPECTED OUTCOME}

The data to be collected from the experiments will be analyzed based on Taguchi method to determine the optimum powder concentration and powder particles size in EDM process. Result from this research work is expected to be useful for EDM user in using the correct amount of powder concentration and powder particles size to achieve the higher efficiency of EDM process. It is envisaged that this will contribute to increase the MRR, improve surface finish, reduce TWR, reduce machining time and reduce machining cost.

\section{CONCLUSION}

EDM process plays a big role in mold manufacturing industries. Due to longer machining time, it machining cost is high. To increase EDM process efficiency, PMEDM was proposed. However further investigations are required before the new PMEDM can be commercialized. This paper proposes investigation on SiC PMEDM powder concentration and powder particles size in cutting Stavax ${ }^{\circledR}$ material. The results are expected to provide information on:

1) The influence of PMEDM in machining Stavax® material in terms of MRR, TWR and Ra.

2) The reduction machining time of EDM process with PMEDM.

3) The optimum powder concentration and size of powder particles to achieve the highest efficiency of EDM process.

\section{REFERENCES}

[1] D. K. Singh, Fundamentals of Manufacturing Engineering, India: Ane Books India, 2008, pp. 449-452.

[2] M. P. Goover, Fundamentals of Modern Manufacturing, John Wiley \& Sons, 2002, pp. 619-623.

[3] W. S. Zhou, Q. G. Meng, and Z. L. Wang, "The application of research on powder mixed edm in rough machining," Journal of Materials Processing Technology, vol. 129, pp. 30-33, 2002.

[4] S. Kumar, R. Singh, T. P. Singh, and B. L. Sethi, "Surface modification by electrical discharge machining: A review," Journal of Materials Processing Technology, vol. 209, pp. 3675-3687, 2009.

[5] Y. F. Tzeng and C. Y. Lee, "Effects of powder characteristics on electrodischarge machining efficiency," The International Journal of Advanced Manufacturing Technology, vol. 17, pp. 586-592, 2001.

[6] H. Kansal, S. Singh, and P. Kumar, "Effect of silicon powder mixed EDM on machining rate of AISI D2 die steel," Journal of Manufacturing Processes, vol. 9, pp. 13-22, 2007.

[7] S. Singh, H. K. Kansal, and P. Kumar, "Parametric optimization of powder-mixed electrical discharge machining by response surface methodology," Journal of Material Processing Technology, vol. 169, pp. 427-436, 2002.

[8] Z. M. Zain, M. B. Ndaliman, A. A. Khan, and M. Y. Ali, "Electro-Discharge Machining of SUS 304 Stainless Steel with TaC Powder-Mixed Dielectric," Advanced Materials Research, vol. 576, pp. 72-75, 2012.

[9] M. S. Rizi, G. R. Razavi, M. Ostadmohamadi, and A. R. Havaie, "Optimization electro discharge machining of Ti-6Al-4V alloy with silicon carbide powder mixed," Advanced Materials Research, vol. 566, pp. 466-469, 2012.

[10] M. Y. Ali, N. A. Rahman, and E. M. Aris, "Powder mixed micro electro discharge milling of titanium alloy: investigation of material removal rate," Advanced Materials Research, vol. 383, pp. 1759-1763, 2012.

[11] A. Batish and A. Bhattacharya, "Mechanism of material deposition from powder, electrode and dielectric for surface modification of $\mathrm{H} 11$ die steel in EDM process," Materials Science Forum, vol. 701, pp. $61-75,2012$.

[12] P. Janmanee and A. Muttamara, "Surface modification of tungsten carbide by electrical discharge coating (EDC) using a titanium powder suspension," Applied Surface Science, vol. 258, pp. 7255-7265, 2012.

[13] H. K. Kansal, S. Singh, and P. Kumar, "Numerical simulation of powder mixed electric discharge machining (PMEDM) using finite element method," Mathematical and Computer Modelling, vol. 47, pp. 1217-1237, 2008. 


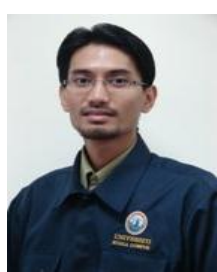

Muhammad Al'hapis Abdul Razak was born in Selangor, Malaysia. He is a lecturer at Universiti Kuala Lumpur Malaysian Spanish Institute. He holds a bachelor degree and master degree in manufacturing engineering technology from Universiti Kuala Lumpur, Malaysia. His research interests are in $\mathrm{CNC}$ and macro programming, STEP-NC, feature-based machining, advanced manufacturing, dielectric fluid and design of experiment (DOE).

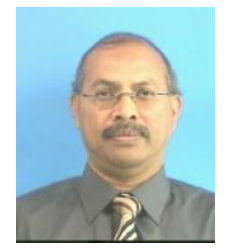

Ahmad Majdi Abdul-Rani is an associate professor in Universiti Teknologi PETRONAS (UTP), Malaysia. He holds a bachelor degree in manufacturing and master degree in industrial engineering both from Northern Illinois University, U.S.A. He obtained his $\mathrm{PhD}$ in mechanical and manufacturing from Loughborough University in the United Kingdom. His research interests are in advanced manufacturing system; rapid prototyping and rapid tooling; reverse engineering; CIM; FMS; CAD/CAM; CNC programming and STEP-NC. A number of $\mathrm{PhD}$ and $\mathrm{MSc}$ candidates had graduated successfully under his supervision. He is currently the principal investigator for four national grants.

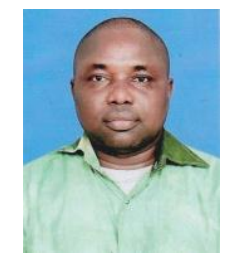

Alexis Mouangue Nanimina was born in Bitkine, Chad. He obtains Diplôme d'Ingénieur des Travaux in 2002 and master degree in mechanical engineering from Institut Universitaire des Sciences et Technique d'Abéché (IUSTA) in 2006, Chad and master of sciences degree in mechanical engineering from Univeriti Teknologi PETRONAS (UTP), Tronoh, Malaysia in 2010. Currently he is a PhD student in mechanical engineering at Univeriti Teknologi PETRONAS (UTP), Tronoh, Malaysia. His research areas are in advanced manufacturing (EDM, high speed machining/HSM) and material (materials characterization including surface integrity), design and analysis of experiment (DOE), modeling and optimization (response surface methodology - RSM). 